\title{
Idiopathic scrotal calcinosis: Case report
}

\author{
AlQahtani Raed ${ }^{1 *}$, Albdawe $\mathrm{Hani}^{2}$ and Saad Abumelha ${ }^{2}$ \\ ${ }^{1}$ Sattam Bin Abdulaziz University, College of Medicine, Surgery Department, Saudi Arabia \\ ${ }^{2}$ Department of Surgery, Division of Urology, King Abdulaziz Medical City, Saudi Arabia
}

\begin{abstract}
This is 26 years old male patient, medically free, presented to our clinic complaining of multiple painless scrotal nodules which are increasing in number in the last few years. The patient was looking for medical treatment mostly due to cosmetic reasons. Our diagnosis was initially pointed towards sebaceous cysts. The patient underwent surgical treatment as day case surgery for removal of the scrotal nodules by elliptical inscion. The surgical pathology of the retrieved specimens showed idiopathic scrotal calcinosis. The idiopathic scrotal calcinosis is rare disease with few cases reported in literatures worldwide.
\end{abstract}

\section{Introduction}

Scrotal calcinosis (SC) is a rare, benign disease with few cases reported in the literature. Defined as the presence of multiple calcified nodules within the scrotal skin. In most cases, there are no associated symptoms [1].

\section{Case report}

This is 26 years old male patient, medically free, presented with multiple scrotal painless nodules variable in sizes, which were increasing in number over the past years. The patient denied any scrotal diseases like infection or trauma. No history of metabolic or autoimmune diseases.

Physical examination showed multiple with different sizes firm nodules over the scrotum 2-10 $\mathrm{mm}$ with no signs of inflammation, infection or ulceration. No investigation was done.

Our Differential diagnosis was:

- Scrotal Sebaceous Cysts

-Scrotal Malignancy

\section{-Calcified Steatocystoma [2]}

Based on the patient history and our deferential diagnosis, we booked the patient for surgery as an outpatient day care case surgery for removal of the scrotal nodules. Under general anesthesia, we did elliptical incisions and some of the nodules we did enucleation, we removed all the nodules which were nine in number. Surgical pathology report showed idiopathic scrotal calcinosis [3] (Figure 1).

Post operation the cosmetic result was excellent and after 6 months of follow up there was no recurrence.

\section{Discussion}

Idiopathic SC is a rare and benign condition, usually appears in men between 20-40 years of age. Scrotal calcinosis is more common in dark colored race and affects mainly males but similar lesions (vulvar calcinosis) has been reported in females.

SC presents with variable sizes, numbers and it has white yellowish color, usually painless and no associated symptoms. Mainly the patient asked for treatment for the cosmetic appearance. The diagnosis usually
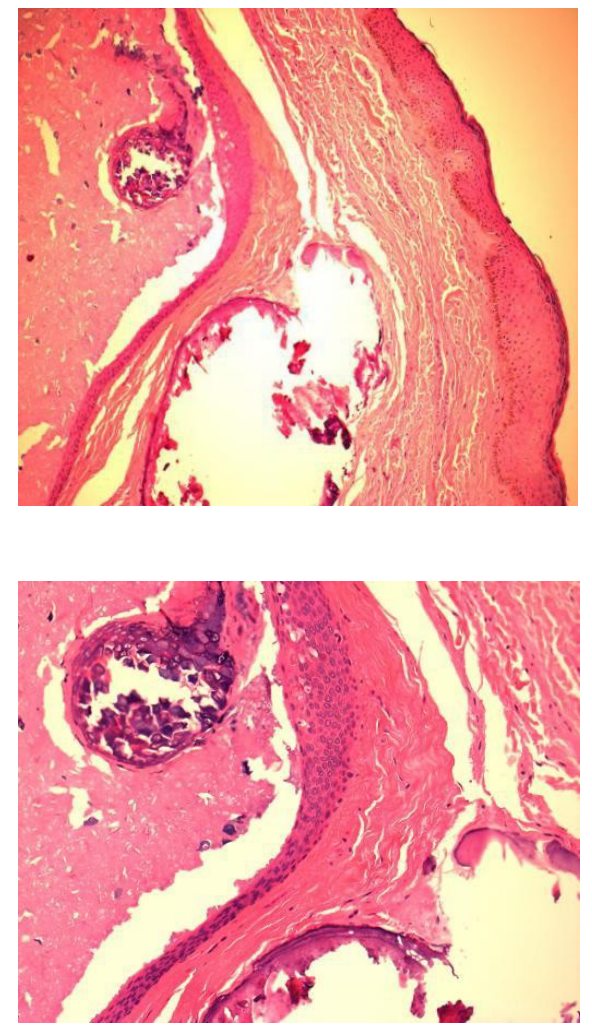

Figure 1. Microphotograph showing lobules of calcific deposit in dermis surrounding by fibrosis (H\&E).

Correspondence to: AlQahtani Raed, Surgery Department, College of Medicine, Sattam Bin Abdulaziz University, Saudi Arabia, Tel: +966560806608; E-mail: raed.alasmi@gmail.com

Received: January 09, 2017; Accepted: January 19, 2017; Published: January 21, 2017 
confirmed by examination under microscope (histopathology). The only treatment recommended is surgery, it must be limited to the scrotal skin since the SC usually limited to the dermis. Recurrence was reported in some cases [4]. The calcification of preexistent epidermal cysts is suggested by many authors as a possible pathogenesis [1]. Dystrophic calcification of epidermal cysts was suggested by some authors, because they found some calcium deposition in the dermis with some giant inflammatory cells.

Shapiro et al. reviewed the histologic data and found no evidence of an epithelial lining, residual cysts, lipid or organisms, and concluded that the calcification was idiopathic introducing the term "idiopathic scrotal calcinosis [2].

\section{Conclusion}

SC is rare benign painless scrotal disease clinically diagnosed with different size and numbers, the surgical excision is the gold standard of treatment with excellent outcome.

\section{References}

1. Saad AG, Zaatari GS (2001) Scrotal calcinosis: is it idiopathic? Urology 57: 365 [Crossref]

2. Killedar MM, Shivani AA, Shinde U (2016) Idiopathic Scrotal Calcinosis. Indian J Surg 78: 329-30. [Crossref]

3. Swineheart JM, Golitz LE (1982) Scrotal calcinosis. Dystrophic calcification of epidermoid cysts. Arch Dermatol 118: 985-988. [Crossref]

4. Salvarci A, Altinay S (2013) Relapsing idiopathic scrotal calcinosis. J Pak Med Assoc 63: 1433-4. [Crossref]

Copyright: (C2017 Raed A. This is an open-access article distributed under the terms of the Creative Commons Attribution License, which permits unrestricted use, distribution, and reproduction in any medium, provided the original author and source are credited. 